\title{
EVALUASI EDIBLE COATING DENGAN PENAMBAHAN EKSTRAK JAHE PADA KARAKTERISTIK FISIKA, KANDUNGAN VITAMIN C, DAN KARAKTERSITIK SENSORIS CABAI MERAH
}

\author{
EVALUATION OF EDIBLE COATING WITH GINGER EXTRACT ADDITION ON PHYSICAL \\ PROPERTIES, VITAMIN C, AND SENSORY ATTRIBUTES ON RED CHILI
}

\author{
${ }^{1)}$ Fitra Sawali Ainunnisa, ${ }^{1)}$ Teguh Pribadi, ${ }^{1)}$ Arif Prashadi Santosa \\ ${ }^{1)}$ Program Studi Agroteknologi, Fakultas Pertanian \\ Universitas Muhammadiyah Purwokerto \\ Jalan Raya KH. Ahmad Dahlan, Po Box 202, Kembaran-Banyumas, Jawa Tengah 53182 \\ *Email:fitrasawaliainunnisa24@gmail.com, tgpribadi@ump.ac.id
}

\begin{abstract}
ABSTRAK
Penelitian ini dilakukan untuk mengevalusi kombinasi edible coating yang diperkaya ekstrak jahe dan lama perendaman pada kualitas produk cabai merah setelah 15 hari penyimpanan. Tiga sampel dari masing-masing perlakukan diukur karakteristik fisikokimianya dengan kontrol. Selanjutnya 21 untrained panelists mengevaluasi karakterstik sensoris cabai merah setelah 15 hari dengan kontrol dan cabai segar. Kombinasi perlakukan belum mampu mempertahankan kualitas produk. Susut bobot, kadar air, kekerasan, dan kandungan vitamin C pada masing-masing perlakukan tidak berbeda dengan kontrol. Bagitu juga dengan uji hedonik, ternyata aplikasi EC yang diberikan belum dapat mempertahankan mutu sensoris cabai. Konsekunsinya perbaikan metode aplikasi edible coating perlu diperbaiki kembali, khususnya kemurniaan ekstrak jahe yang digunakan.
\end{abstract}

Kata Kunci: edible coating, ekstrak jahe, lama pencelupan, lama penyimpanan, mutu cabai merah

\section{ABSTRACT}

This research was conducted to evaluate the combination of edible coating enriched with ginger extract and the immersion time on the quality of red chili after 15 days of storage. Three samples from each treatment were measured for their physicochemical properties and compared with the control. Furthermore, 21 untrained panelists evaluated red chilies' sensory characteristics after 15 days with untreated and fresh red chilies. Our results showed the treatment combination has not been able to maintain product quality. The weight loss, moisture content, hardness, and vitamin $C$ content in each treatment did not differ from the control. Likewise, with the hedonic test, it turns out that the EC application given has not been able to maintain the sensory quality of red chilies. Consequently, the edible coating application method's improvement needs to be improved again, especially the ginger extract's purity.

Keywords: edible coating, ginger extract, immersion time, storage time, red chilies quality.

\section{PENDAHULUAN}

Cabai merah (Capsicum annum L.) merupakan salah satu jenis sayuran yang penting dan bernilai ekonomis tinggi baik (Wardani dan Purwanta, 2008). Kebutuhan masyarakat terhadap komoditas cabai semakin meningkat sejalan dengan pertambahan jumlah penduduk (Harpenas dan Dermawan, 2008) dengan kebutuhan sebanyak 1,46 kg per individu pada tahun 2015 (Suyanti, 2018). Selain sebagai rempah-rempah, cabai merah memiliki kandungan vitamin C yang tinggi 18 mg per 100 g cabai merah segar (Wiryanta, 2002). Di samping itu, kandungan capsaicin pada cabai merah bersifat antiradang dan antikoagulan (Suyanti, 2007).

Namun demikian, produk hortikultura umumnya memiliki umur simpan yang pendek. Cabai merah yang disimpan ditempat terbuka hanya mampu bertahan dua sampai lima hari (Rizeki et al., 2016). Kadar air cabai merah yang tinggi meningkatkan resiko kerusakan pada produk selama proses penyimpanan, (Budiarti dan Kurnianingrum, 2015; Vebriansyah, 2017). Pemanfaatan edible coating (EC) diharapkan dapat mempertahankan mutu serta meningkatkan umur simpan cabai merah pada suhu ruangan $\left(25^{\circ} \mathrm{C}\right)$ (Erviani et al., 2017).

Edible coating (EC) merupakan suatu lapisan tipis, terbuat dari bahan yang dapat dikonsumsi dan dapat berfungsi sebagai pembatas agar tidak kehilangan kelembaban serta mampu mengontrol perpindahan komponen-komponen larut air yang dapat menyebabkan perubahan pigmen dan kandungan nutrisi bahan 
(Baldwin et al., 2012). Selain itu penggunaannya juga dimaksudkan untuk memperpanjang masa simpan dan memperbaiki kualitas produk pangan (Fauziati et al., 2016).

Salah satu faktor yang mempengaruhi keberhasilan dalam aplikasi EC adalah lama pencelupan. Lamanya proses pencelupan dapat meningkatkan proses pelapisan permukaan dengan lebih merata (Christina, 2017). Beberapa penelitian menunjukan bahwa lama pencelupan (satu sampai lima menit) mampu memperpanjang umur simpan cabai merah (Rukhana, 2017), cabai rawit (Rustan et al., 2017), dan stroberi (Hendrawan et al., 2017) yang berkisar dari lima sampai 15 hari.

Penambahan bahan antrimikroba dalam pembuatan EC mampu meningkatkan kestabilan EC dan membantu memperpanjang masa simpan buah yang dilapisi (Sari et al., 2018). Salah satu sumber antimikroba alami yaitu rimpang jahe. Rimpang jahe mengandung senyawa golongan fenol, flavonoid, terpenoid, dan minyak atsiri yang merupakan golongan senyawa bioaktif yang dapat menghambat pertumbuhan mikroba (Kurniasari et al., 2008; Sari et al., 2018). Penggunaan Ekstrak jahe untuk EC pada cabai merah dilaporkan mampu meningkatkan umur simpan yang lebih baik dibandingkan dengan ekstrak lengkuas, kunyit, dan temulawak (Rukhana, 2017).

Penambahan bahan antimikroba berupa ekstrak jahe dalam pembuatan EC terbukti efektif untuk mempertahankan mutu buah. Namun demikian pemanfaatan ekstrak jahe sebagai bahan antimikroba pada pembuatan EC berbasis pati belum banyak dikaji. Disamping itu informasi tentang lama pencelupan yang efektif pada EC berbasis pati dengan penambahan ekstrak jahe sebagai antimikroba juga masih sedikit dilakukan. Oleh karena itu, tujuan penelitian ini adalah mengevaluasi efisiensi EC dengan penambahan ekstrak jahe dan lama perendaman dalam mempertahankan mutu cabai merah.

\section{METODE}

Bahan-bahan. EC berupa tepung tapioka instant (merek Rose Brand), jahe gajah (Zingiber officinale Roscoe var officinale) yang diperoleh dari Kecamatan Kroya dan dipanen pada umur delapan bulan, aquades, gliserol, dan carboxymethyl cellulose (CMC). Objek aplikasi EC yaitu cabai merah (Capsicum annum L.) yang berwarna merah, panjang $\pm 10 \mathrm{~cm}$, dengan umur satu hari setelah panen yang diambil langsung dari perkebunan milik petani di Desa Bunton, Adipala, Cilacap. Bahan untuk analisis kadar vitamin C yaitu amilum, aquades dan iod. Bahan untuk uji daya hambat yaitu media Potato Dextrose Agar (PDA), media Potato Dextrose Broth (PDB), isolat jamur Colleotrichum capsici yang diperoleh dari Institut Pertanian Bogor (IPB), alkohol 70\%, dan alkohol 96\%.

Pembuatan Ekstrak Jahe. Rimpang jahe berkualitas dan tidak busuk dipilih selanjutnya direndam dalam aquadest selama 24 jam. Selanjutkan rimpang dipisahkan dari kulitnya dicuci. Jahe yang sudah bersih kemudian diparut dan diperas dengan kain saringan, sari jahe yang terbentuk kemudian diendapkan. Sari jahe yang terbentuk digunakan sebagai bahan antimikroba selanjutnya diencerkan menjadi tiga konsentrasi yang berbeda, yaitu 6\%, 8\%, dan 10\% (v/v) (Rukhana, 2017 dengan modifikasi). Sari jahe inilah yang digunakan sebagai larutan EC pada penelitian ini.

Pengujian Aktivitas Antimikroba. Metode difusi kertas cakram diterapkan pda penelitian ini. Satu ose spora $C$. capsici diinokulasi dari agar miring PDA ke dalam $10 \mathrm{~mL}$ media cair PDB secara aseptik. Kultur uji kemudian diinkubasi selama 24 jam pada suhu $25-27^{\circ} \mathrm{C}$. Kemudian untuk media pertumbuhan jamur, PDA sebanyak sebanyak 15,795 g dilarutkan dalam $405 \mathrm{ml}$ aqauades dan disterilisasi di dalam autoklaf selama 15 menit. Selanjutnya media PDA dimasukkan ke dalam setiap cawan petri sebanyak $15 \mathrm{ml}$ dan inokulum $C$. capsici sebanyak $0,1 \mathrm{~mL}$ dituangkan ke dalam media lalu dibiarkan memadat. Kertas cakram dengan diameter $5 \mathrm{~mm}$ diletakkan di atas media agar PDA yang sebelumnya telah direndam dalam larutan EC selama 20 menit. Cawan petri diinkubasi pada suhu $25-27^{\circ} \mathrm{C}$ selama 3 hari. Setelah melalui masa inkubasi, akan muncul zona penghambatan dan dilakukan pengukuran diameter zona penghambatan. Diameter zona penghambatan (DZH) dihitung berdasarkan diameter zona bening yang terbentuk (Wisudawaty et al., 2016). 
Keterangan:

$$
D Z H=\frac{(D v-D c)+(D h-D c)}{2}
$$

$\begin{array}{ll}D Z H & \text { : Diameter Zona Hambat }(\mathrm{mm}) \\ D v & \text { : Diameter vertikal }(\mathrm{mm}) \\ D h & \text { : Diameter horisontal }(\mathrm{mm}) \\ D c & \text { : Diameter cakram }(\mathrm{mm})\end{array}$

Pembuatan \& Aplikasi Larutan EC. Suspensi CMC 0,4\% (m/v) dilarutan dalam aquadest $500 \mathrm{ml}$ dan diaduk sampai merata. Kemudian dibuat laurtan tapioka pada aquadest dengan konsentrasi $3 \%(\mathrm{~m} / \mathrm{v})$ dan diaduk sampai merata. Selanjutnya larutan tersebut dipanaskan pada suhu $70^{\circ} \mathrm{C}$ dan ditambahkan gliserol $5 \%(\mathrm{v} / \mathrm{v})$. Langkah selanjutnya masing-masing EC ditambahkan ekstrak jahe dengan konsentrasi sesuai perlakukan yang diaplikasikan. Selanjutnya cabai merah dicelupkan pada masing-masing larutan dengan suhu $65^{\circ} \mathrm{C}$ selama 1 detik, 60 detik, 180 detik dan 300 detik. Langkah berikutnya cabai merah yang sudah dicelupkan kemudian digantung pada rak strimin selama 24 jam. Cabai merah yang sudah diaplikasikan kemudian disimpan pada rak strimin selama 15 hari pada suhu ruangan (Rukhana, 2017. dengan modifikasi).

Pengamatan Karakteristik Fisika. Pengukuran susut bobot (SB), kadar air (KA), kekerasan (Ke) dilakukan pada setiap sampel pada awal aplikasi (H0) dan akhir pengamatan (H15). SB diukur dengan menghitung berat sampel pada H15 dan H0 (Rukhana, 2017). KA dilakukan dengan menimbang sampel dan dimasukan dalam cawan petri selanjutkan dikeringkan dengan suhu $105^{\circ} \mathrm{C}$ selama satu jam (B0). Selanjutnya sampel dipanaskan pada suhu $105^{\circ} \mathrm{C}$ selama 24 jam, kemudian didinginkan dalam desikator selanjutnya ditimbang beratnya (B1) (AOAC, 1995 dalam Rukhana, 2017). Tingkat kekerasan cabai merah dilakukan dengan penetrometer pada H0 dan H15 (Seruni, 2018).

Keterangan:

$$
S B=\frac{A-B}{A} \times 100 \%
$$

SB : Susut bobot (\%).

A : Bobot sebelum diberi perlakuan/ bobot hari ke-0 (gram).

B : Bobot cabai pada hari ke-15 setelah diberi perlakuan (gram).

Keterangan:

$$
K A=\frac{B 0-B 1}{B 0} \times 100 \%
$$

KA : Kadar air $(\%)$.

B0 : berat sampel awal/sebelum dioven (gram).

B1 : berat sampel akhir/setelah dioven (gram).

Pengukuran Kandungan Vitamin C. Pengukuran vitamin C dilakukan pada H0 dan H15. Sepuluh gram sampel dihancurkan kemudian dimasukan dalam labu erlenmayer dengan air destilat sampau tanda tera. Selanjutnya larutan tersebut disaring dengan kertas saring. Filtrat yang diperoleh ebanyak $25 \mathrm{ml}$ dimasukan dalam labu Erlenmeyer, ditambahkan 2-3 tetes amilum 1\% dan dititrasi dengan larutan Iodine 0,01 N sampai terbentuk warna stabil (biru ungu). Setiap satu mililiter Iodine setara dengan $0,88 \mathrm{mg}$ asam askorbat. Perhitungan kadar vitamin C (VC) mengacu pada formula yang digunakan oleh Rukhana, 2017).

Keterangan:

$$
V C=\frac{m l \text { iod } 0,01 N \times 0,88 \times F p}{\text { berat contoh }(\text { gram })} \times 100 \%
$$

VC : Kadar vitamin C (\%).

Fp : Faktor pengencer.

Pemantauan Karakteristik Sensori. Karakteristik cabai setelah aplikasi dievaluasi oleh 21 untrained panelis yang berasal dari mahasiswa agroteknologi dengan usia 19-22 tahun. Sebelum pengujian mereka disampaikan terkait tujuan penelitian dan dilatih menggunakan pengujian hedonik pada skala lima. Lima skoring uji hedonik meliputi warna (5, oranye; 1 , coklat), kesegaran (5, sangat segar; 1 , layu), dan kesukaan (5, sangat suka; 1, sangat tidak suka). Pengujian sensori dilakukan pada H15 pada satu waktu dimana panelis disajikan dan menilai 14 sampel uji (sesuai perlakukan) secara acak.

Analisis Statistika. Percobaan disusun dalam format rancangan acak lengkap dan diulang sebanyak tiga kali untuk masing-masing perlakuan. Data parametrik disajikan dalam nilai rata-rata \pm simpangan baku. Analisis ragam yang diikuti oleh uji Duncan pada taraf nyata 0,05 diterapkan untuk semua data parametrik (daya hambat, susut bobot, kadar air, tingkat kekerasan, dan kandungan vitamin C) serta dianalisis dengan perangkat lunak Costat 6.311 (https://www.cohort.com/costat.html). Transformasi Box-Cox digunakan memenuhi persyaratan pengujian parametrik (data menyebar normal \& ragam antar kelompok perlakuan sama) dan 
dibangkitkan dengan bantuan perangkat lunak PAST 4.01 (Hammer et al., 2001). Sedangkan data nonparametrik (analisis sensori) ditampilkan dengan nilai median (nilai terendah - nilai tertinggi) (Trani et al. 2016). Analisis Kruskal-Wallis yang diikuti dengan uji Dunn Post-Hoc pada taraf nyata 0,05 diterapkan pada kelompok data ini atau tidak memenuhi persyaratan parametrik (daya hambat) yang dianalisis dengan perangkat lunak PAST 4.01 (Hammer et al., 2001).

\section{HASIL DAN PEMBAHASAN}

Aktivitas antimikroba. Pengujian ekstrak jahe pada tiga konsentrasi yang berbeda menunjukan nilai yang berbeda. Secara umum terdapat kecenderungan bahwa konsentrasi ekstrak jahe yang makin tinggi maka daya hambatnya makin baik (Gambar 1.) Namun, uji statistika menunjukan bahwa konsentrasi ekstrak jahe tidak berpengaruh terhadap perkembangan diameter jamur $C$. capsici pada percobaan ini $\left(X^{2}=1,64 ; d b=2, p=\right.$ 0,4399). Hasil pengujian ini kontrakdiktif dengan penelitian yang dilakukan oleh Suleiman dan Emua (2009) dan Mujim (2010). Perbedaan hasil pengujian ini diduga karena perbedaan metode ekstraksi. Pemarutan rimpang jahe belum efektif mengeluarkan senyawa minyak atsiri rimpang jahe yang memiliki sifat antijamur. Ekstraksi minyak atsiri biasanya dilakukan dengan pelarut organik seperti aseton, etanol, diklorometana, dikloroetana, atau trichloroethane dengan metode ekstraksi berupa maserasi, maserasi yang dimodifikasi, perkolasi, atau ekstraksi soxhlet (Jayanudin et al., 2019).

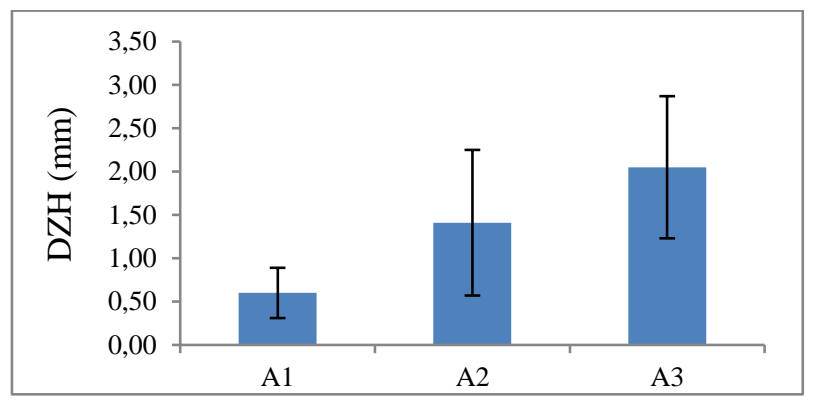

Gambar 1. Pengaruh konsentrasi ekstrak jahe (A) dalam menghambat pertumbuhan $C$. capsici diukur berdasarkan diameter zona hambat/DZH $(\mathrm{cm})$. Nilai disajikan rata-rata \pm simpangan baku. $n=6$.

Karakteristik fisikokimia. Pemberian ekstrak jahe dan peningkatan lama perendaman secara umum belum mampu mempertahankan mutu cabai merah setelah disimpan 15 hari (Tabel 1). Pemberian EC dengan ekstrak jahe pada konsentrasi dan lama perendaman tidak mampu mengurangi susut bobot cabai setelah $\mathrm{H} 15\left(F_{(12,38)}=\right.$ $1,089 ; p=0,408)$. Perlakukan yang dicobakan hanya mampu menurunkan susut bobot $<10 \%$ dan ini tidak sepenuhnya dipengaruhi perlakukan yang diberikan. Fenomena yang sama juga terbentuk pada kadar air $\left(F_{(12,38)}=0,830 ; p=0,621\right)$ dan tingkat kekerasan $\left(F_{(12,38)}=1,292 ; p=0,281\right)$. Kemampuan EC untuk melindungi permukaan cabai merah dari proses transpirasi dan respirasi tidak berjalan dengan baik. Hal ini sesuai dengan penelitian yang dilakukan oleh Fauziati et al. (2016). Dimana Mukhtarom et al., (2016) menjelaskan bahwa susut bobot terjadi disebabkan adanya proses respirasi dan transpirasi yang mengakibatkan komoditas hortikultura berkurang cadangan makanannya dan kehilangan air melalui penguapan. Ini diperkautan dengan hasil penelitian ini yang menunjukan bahwa kadar air dan kerasan sampel relatif rendah dimana nilainya berturut-turut $<50 \%$ dan $<0,60 \mathrm{~mm} \cdot \mathrm{g}^{-1} \cdot \mathrm{s}^{-1}$. Kemampuan melapisi dari EC salah satunya ditentukan oleh kandungan amilosa bahan pelapis (Lathifa, 2013). Tepung tapioka memiliki kadar amilosa yang rendah $(<20 \%)$ sehingga kemampuan melapisi rendah dan kurang sempurna. Dampak lanjutannya kadar air dan tingkat kekerasan cabai merah tidak beda dengan kontrol. Semakin banyak air yang berkurang, semakin besar susut bobot maka sayuran akan semakin lunak (Viǹa et al., 2007).

Kandungan Vitamin C menunjukan hasil yang tidak jauh berbeda dengan kedua variabel di sebelumnya (Tabel 1). Dimana perlakukan yang diterapkan belum memberikan bukti yang cukup yang menjelsakan bahwa mempertahankan kandungan vitamin $\mathrm{C}\left(F_{(12,38)}=1,068 ; p=0,4231\right)$. Hal ini seperti yang dilakukan oleh Siburian (2015) pada buah tomat dan Miskiyah et al. (2011) pada buah paprika. Hal tersebut dikarenakan kadar vitamin $\mathrm{C}$ dalam cabai merah dipengaruhi oleh proses transpirasi yang menyebabkan kadar air dalam cabai berkurang (Ibrahim et al., 2015). Penurunan kadar air juga akan menambah tingginya kadar zat gizi yang tertinggal (Nilasari et al., 2017). 
Tabel 2. Sifat fisikokimia cabai merah yang diberikan perlakukan aplikasi EC dengan penambahan ekstrak jahe (A) dan lama perendaman (L) setelah 15 hari penyimpanan pada suhu kamar.

\begin{tabular}{ccccc}
\hline Perlakuan & $\begin{array}{c}\text { Susut bobot } \\
(\%)\end{array}$ & $\begin{array}{c}\text { Kadar air } \\
(\%)\end{array}$ & $\begin{array}{c}\text { Tingkat kekerasan } \\
\left(\mathrm{mm} \cdot \mathrm{g}^{-1} \cdot \mathrm{s}^{-1}\right)\end{array}$ & $\begin{array}{c}\text { Vitamin C } \\
(\%)\end{array}$ \\
\hline A1L0 & $71,44 \pm 1,67$ & $46,54 \pm 8,33$ & $0,56 \pm 0,02$ & $3,78 \pm 0,99$ \\
A1L1 & $70,63 \pm 2,23$ & $52,70 \pm 6,55$ & $0,60 \pm 0,01$ & $4,27 \pm 1,15$ \\
A1L2 & $72,07 \pm 1,67$ & $50,22 \pm 12,41$ & $0,58 \pm 0,03$ & $3,26 \pm 0,49$ \\
A1L3 & $76,73 \pm 2,70$ & $44,72 \pm 2,88$ & $0,59 \pm 0,01$ & $2,99 \pm 0,35$ \\
A2L0 & $72,75 \pm 3,16$ & $49,27 \pm 7,12$ & $0,56 \pm 0,02$ & $1,83 \pm 0,94$ \\
A2L1 & $75,18 \pm 5,53$ & $45,57 \pm 4,65$ & $0,60 \pm 0,02$ & $3,23 \pm 1,50$ \\
A2L2 & $77,91 \pm 1,94$ & $42,58 \pm 7,63$ & $0,59 \pm 0,03$ & $2,37 \pm 0,82$ \\
A2L3 & $77,21 \pm 1,34$ & $36,38 \pm 10,2$ & $0,58 \pm 0,03$ & $3,87 \pm 0,62$ \\
A3L0 & $75,07 \pm 3,14$ & $42,31 \pm 4,46$ & $0,59 \pm 0,02$ & $2,13 \pm 1,05$ \\
A3L1 & $76,91 \pm 0,95$ & $48,06 \pm 8,98$ & $0,58 \pm 0,02$ & $3,61 \pm 0,32$ \\
A3L2 & $73,42 \pm 2,71$ & $37,72 \pm 7,10$ & $0,57 \pm 0,02$ & $1,78 \pm 0,17$ \\
A3L3 & $78,02 \pm 0,22$ & $38,39 \pm 6,98$ & $0,66 \pm 0,01$ & $2,99 \pm 0,09$ \\
kontrol & $71,87 \pm 0,81$ & $60,78 \pm 0,86$ & $0,59 \pm 0,01$ & $2,82 \pm 0,18$ \\
\hline
\end{tabular}

Keterangan: huruf yang berbeda yang mengikuti angka pada kolom yang sama menunjukan perbedaan secara nyata hasil uji Duncan $(p<0,05)$. Nilai disajikan rata-rata \pm simpangan baku. $n=3$.

Evaluasi sensori. Hasil lengkap evaluasi sensoris cabai merah setelah aplikasi oleh 21 untrained panelist disajikan pada Tabel 2. Secara umum perlakuan yang diberikan memberikan penurunan persepsi dari panelis jika dibandingkan dengan cabai segar (Kontrol +). Meskipun demikian warna yang dihasilkan, khususnya perlakuan A3L1 mendekati kontrol $+\left(X^{2}=86,38 ; d b=13, p=<0,001\right)$. Sedangkan pada kesegaran menunjukan persepsi yang menurun $\left(X^{2}=87,43 ; d b=13, p=<0,001\right)$ sehingga menurunkan kesukaan panelis $\left(X^{2}=93,44 ; d b=13, p=<0,001\right)$. Hasil ini mengindikasikan bahwa aplikasi EC dengan penambahan ekstrak jahe belum mampu mempertahankan mutu setelah penyimpanan di suhu ruangan selama 15 hari.

Penambahan diduga ekstrak jahe belum efektif melindungi cabai merah dari infestasi mikroba. Hasil pengujian efektvitas ekstrak jahe mendukung fakta tersebut (Gambar 1.). Disamping itu, kandungan pati pada EC mendukung perkembangan $C$. capsici (Rani et al. 2013) begitu juga dengan suhu EC yang tinggi dapat mempengaruhi karakteristik fisika cabai merah (Sarastuti \& Yuwono, 2015; Asgar et al. 2017) sehingga umur simpan cabai merah pada suhu kamar makin pendek karena kerusakan sel cabai merah. Secara umum tampilan fisik produk pertanian memegang peranan penting terhadap persepsi konsumen (Ogutchu et al. 2017). Produk pertanian dengan warna yang menarik, tampilan yang segar akan meningkatkan kesukaan/preferensi konsumen.

Tabel 2. Profil sensori cabai merah yang diberikan perlakukan aplikasi EC dengan penambahan ekstrak jahe (A) dan lama perendaman (L) setelah 15 hari penyimpanan pada suhu kamar .

\begin{tabular}{cccc}
\hline Perlakuan & Warna & Kesegaran & Kesukaan \\
\hline A1L0 & $4(3-5) \mathrm{bcde}$ & $2(1-4) \mathrm{b}$ & $2(1-4) \mathrm{bc}$ \\
A1L1 & $4(2-5) \mathrm{abc}$ & $2(1-4) \mathrm{b}$ & $2(1-4) \mathrm{bc}$ \\
A1L2 & $4(2-5) \mathrm{bcde}$ & $2(1-3) \mathrm{b}$ & $2(1-3) \mathrm{bc}$ \\
A1L3 & $3(1-5) \mathrm{de}$ & $1(1-3) \mathrm{b}$ & $1(1-2) \mathrm{c}$ \\
A2L0 & $3(3-5) \mathrm{bcde}$ & $2(1-3) \mathrm{b}$ & $2(1-3) \mathrm{bc}$ \\
A2L1 & $4(2-5) \mathrm{abc}$ & $2(1-4) \mathrm{b}$ & $2(1-3) \mathrm{bc}$ \\
A2L2 & $3(1-5) \mathrm{bcde}$ & $2(1-4) \mathrm{b}$ & $2(1-3) \mathrm{bc}$ \\
A2L3 & $3(1-5) \mathrm{cde}$ & $2(1-3) \mathrm{b}$ & $2(1-3) \mathrm{bc}$ \\
A3L0 & $3(3-5) \mathrm{bcde}$ & $2(1-4) \mathrm{b}$ & $2(1-3) \mathrm{bc}$ \\
A3L1 & $4(2-5) \mathrm{ab}$ & $2(1-4) \mathrm{b}$ & $2(1-3) \mathrm{bc}$ \\
A3L2 & $3(1-5) \mathrm{e}$ & $2(1-4) \mathrm{b}$ & $2(1-4) \mathrm{bc}$ \\
A3L3 & $3(1-5) \mathrm{e}$ & $2(1-3) \mathrm{b}$ & $2(1-3) \mathrm{bc}$ \\
Kontrol & $4(3-5) \mathrm{abcd}$ & $3(1-4) \mathrm{b}$ & $3(1-4) \mathrm{b}$ \\
Kontrol + & $5(3-5) \mathrm{a}$ & $5(1-5) \mathrm{a}$ & $5(4-5) \mathrm{a}$ \\
\hline
\end{tabular}

Keterangan: huruf yang berbeda yang mengikuti angka pada kolom yang sama menunjukan perbedaan secara nyata hasil uji Dunn Post-Hoc $(\mathrm{p}<0,05)$. Nilai yang disajikan adalah median (skor terendah - skor tertinggi). Kode perlakukan merujuk pada Tabel 1. Kontrol - (tanpa perlakuan), Kontrol + (cabai merah segar). 


\section{KESIMPULAN}

Aplikasi EC dengan penambahan ekstrak jahe dan lama perendaman belum mampu mempertahankan kualitas produk cabai merah setelah 15 hari penyimpanan pada suhu ruangan. Ciri fisikokimia produk (susut bobot, kadar air, tingkat kekerasan, dan kadar air) tidak menunjukan hasil yang lebih baik dibandingkan dengan tanpa aplikasi EC. Uji hedonik juga menunjukan hasil yang serupa dimana waran cenderung berubah lebih rendah kualitasnya dan tingkat kesegaran yang berkurang sehingga menurunkan kesukaan dari konsumen. Namun ini membuktikan bahwa keberterimaan produk pertanian ditentukan oleh penampilan produk (contohnya warna dan tingkat kesegaran). Pengembangan EC dengan bahan dasar dengan kandungan amilosa dan penambahan bahan antimikroba berbasis produk alam perlu dilanjutkan.

\section{DAFTAR PUSTAKA}

Asgar, A. (2017). Pengaruh suhu penyimpanan dan jumlah perforasi kemasan terhadap karakteristik fisik dan kimia brokoli (Brassica oleracea var . Royal G) fresh-cut. J. Hort., 27(1): 127-136. http://doi.org/10.21082/jhort.v27n1.2017.-127-136.

Association of Official Analytical Chemists (AOAC). (1995). Official methods of analysis. 16th Ed. AOAC, Washington.

Baldwin, E. A., Hagenmaier, R., \& Bai, J (eds). 2012. Edible coating and film to improve food quality. $2^{\text {nd }}$ Ed. CRC Press, Boca Raton.

Budiarti, A. \& Kurnianingrum, D. A. E. (2015). Pengaruh suhu dan lama penyimpanan terhadap kandungan vitamin $\mathrm{C}$ dalam cabai merah (Capsicum annuum. L) dan aktivitas antioksidanya. Anas, Y (ed). Prosiding Seminar Nasional Peluang Herbal sebagai Alternatif Medicine (Hal: 134-140). Fakultas Farmasi Universitas Wahid Hasyim, Semarang.

Christina, M. (2017). Pengaruh suhu penyimpanan dan lama pencelupan edible coating berbasis nata de coco terhadap karakteristik buah potong Melon. (Skripsi tidak dipublikasikan). Fakultas Teknik Universitas Pasundan, Bandung.

Erviani, U., Ansharullah, \& Wahab, D. (2017). Aplikasi edible coating berbasis pati sagu dengan penambahan filtrat jahe untuk meningkatkan daya simpan cabai merah (Capsicum annum L.). J. Sains dan Tekn. Pangan, 2(6): 931-940. http://dx.doi.org/10.33772/jstp.v2i6.3869.

Fauziati, Adiningsih, Y., \& Priatni, A. (2016). Pemanfaata sterin kelapa sawit sebagai edible coating buah jeruk. J. Riset Tekn. Industri, 10(1): 64-69.

Hammer, O., Harper, D.A.T., Ryan, P.D. (2001). PAST: Paleontological statistical software package for education and data analysis. Paleontologia Electronica, 4(1). 1-8.

Harpenas, A. \& Dermawan, R. (2008). Budi daya cabai unggul. Penebar Swadaya, Jakarta.

Hendrawan, Y., Sumarlan, S. H. \& Ilham, N. A. Z. (2017). Pengaruh konsentrasi ekstrak cincau hijau (Premna oblongifolia L.) sebagai edible coating dan lama pencelupan terhadap kualitas stroberi (Fragaria sp.). $J$. Keteknikan Pert. Trop. \& Biosistem, 5(1): 35-48.

https://www.cohort.com/costat.html.

Ibrahim, A. M., Yunianta \& Sriherfyna, F. H. (2015). Pengaruh suhu dan lama waktu ektrkasi terhadap sifat kimia dan fisika pada pembuatan minuman sari jahe merah (Zingiber officinale var. Rubrum.) dengan kombinasi penambahan madu sebagai pemanis. J. Pangan \& Agroindustri, 3(2): 530-541.

Jayanudin, Rochmadi, Fahruuuozi, M., \& Wirawan, S. K. (2019). Peluang oleoresin jahe sebagai sumber bahan baku berkelanjutan untuk 0bat-obatan. J. Integrasi Proses, 8(2): 82-90. http://dx.doi.org/10.36055/jip.v8i2.6776.

Kurniasari, L., Hartati, I. \& Ratnani, R. D. (2008). Kajian ekstraksi minyak jahe menggunakan microwave assisted extraction (Mae). J. Momentum, 4(2): 47-52. http://dx.doi.org/10.36499/jim.v4i2.622.

Lathifa, H. (2013). Pengaruh jenis pati sebagai bahan dasar edible coating dan suhu penyimpanan terhadap kualitas buah tomat (Lycopersicon esculentum Mill.). (Skripsi yang tidak dipublikasikan). Fakultas Sains dan Teknologi UIN Maulana Malik Ibrahim, Malang.

Miskiyah, Widaningrum, \& Winarti, C. (2011). Edible coating berbasis pati sagu dan vitamin C untuk meningkatkan daya simpan paprika merah (Capsicum annum var. Athena)', J. Penelitian Pascapanen, 8(1): 39-46. http://dx.doi.org/10.21082/jpasca.v8n1.2011.39-46. 
Mujim, S. (2010). Pengaruh ekstrak rimpang jahe (Zingiber officinale Rosch.) terhadap pertumbuhan Pythium sp. penyebab penyakit rebah kecambah mentimum secara in vitro. J. HPT Tropika, 10(1): 59-63. https://doi.org/10.23960/j.hptt.11059-63.

Mukhtarom, K., Sutrisno \& Hasbullah, R. (2016). Perlakuan air panas diikuti pencelupan dalam larutan $\mathrm{CaCl} 2$ untuk mempertahankan kualitas buah belimbing manis (Averrhoa Carambola L.). J. Keteknikan Pertanian, 4(1): 37-44. https://doi.org/10.19028/jtep.04.1.37-44.

Nilasari, O. W., Susanto, W. H. \& Maligan, J. M. (2017). Pengaruh suhu dan lama pemasakan terhadap karakteristik lempok labu kuning (waluh). J. Pangan \& Agroindustri, 5(3): 15-26.

Ogutchu, M,. Arifoglu, N., Yilmaz, E. (2017). Restriction of migration in tahini halva via organogelatin. Eur. J. Lipid Sci. Technol., 119: 1-12.

Rani, S. E. P., Efri \& Prasetyo, J. (2013). Pengaruh berbagai tingkat fraksi ekstrak daun mengkudu (Morinda citrifolia L.) terhadap pertumbuhan Colletotrichum capsici penyebab penyakit antraksnosa pada cabai (Capsicum annum L.) secara in vitro. J. Agrotek Tropika, 1(1): 92-97. http://dx.doi.org/10.23960/jat.v1i1.1923.

Rizeki, E. Supriatna, \& Samingan. (2016). Pengaruh pemberian ekstrak daun gulma siam (Chromolaena odorata L.) dan lama perendaman terhadap pengawetan cabai merah (Capsicum annum L.). J. Ilmiah Mahasiswa Pend. Biol, 1(1): 29-45.

Rukhana, I. S. 2017. Pengaruh lama pencelupan dan penambahan bahan pengawet alami dalam pembuatan edible coating berbahan dasar pati kulit singkong terhadap kualitas pascapanen cabai merah (Capsicum annum L.). ((Skripsi yang tidak dipublikasikan). Fakultas Sains dan Teknologi UIN Maulana Malik Ibrahim, Malang.

Rustan, N. D., Ansharullah \& Asyik, N. (2017). Aplikasi edible coating berbasis pati sagu dengan penambahn asam sitrat untuk meningkatkan daya simpan cabai rawit (Capsicum frustescens). J. Sains \& Tekn. Pangan, 2(6): 997-1005. http://dx.doi.org/10.33772/jstp.v2i6.3876.

Sarastuti, M. and Yuwono, S. S. (2015. Pengaruh pengovenan dan pemanasan terhadap sifat-sifat bumbu rujak cingur instan selama penyimpanan. Jurnal Pangan dan Agroindustri, 3(2): 464-475.

Sari, A. M., Ansharullah dan Asyik, N. (2018). Pengaruh aplikasi edible coating berbasis pati sagu dengan penambahan filtrat kunyit (Curcuma domestika valet) terhadap karakteristik organoleptik tomat segar. J. Sains \& Tekn. Pangan, 3(2): 1129-1139.

Seruni, I. P. (2018). Optimasi proses penyimpanan tomat Cherry (Lycopersicum esculentum var. cerasiforme) dengan perlakuan edible coating pektin cincau hijau (Premna oblongifolia) dan penambahan bubuk jahe (Zingiber officinale var. amarum). (Skripsi yang tidak dipublikasikan). Fakultas Pertanian Universitas Lampung, Bandar Lampung.

Siburian, H. P. (2015). Aplikasi edible coating Aloe Vera kombinasi ekstrak jahe pada buah tomat selama penyimpanan. (Skripsi yang tidak dipublikasikan). Fakultas Pertanian Universitas Lampung, Bandar Lampung.

Suleiman, M. N. \& Emua, S. A. (2009). Efficacy of four plant extracts in the control of root rot disease of cowpea (Vigna unguiculata [L.] Walp). African J. of Biotech., 8(16): 3806-3808.

Suyanti. (2007). Membuat aneka olahan cabai. Penebar Swadaya, Jakarta.

Suyanti. (2018). Membuat 6 olahan cabai. Penebar Swadaya, Jakarta.

Trani, A., Gambacorta, G., Loizzo, P., Cassone, A., Faccia, M, (2016). Short communication: Chemical and sensoty characteristics of Canestrato di Moliterno chees manufactured in spring. J. Dairy Sci., 99. 60806085. http://doi.org/10.3168/jds.2016-10899.

Vebriansyah, R. (2017). Tingkatkan produktivitas cabai. Penebar Swadaya, Jakarta.

Viña, S. Z. et al. (2007). Effects of polyvinylchloride films and edible starch coatings on quality aspects of refrigerated Brussels sprouts. Food Chemistry, 103(3): 701-709. https://doi.org/10.1016/j.foodchem.2006.09.010.

Wardani, N. \& Purwanta, J. H. (2008). Teknologi budidaya cabai merah. Balai Besar Pengkajian dan Pengembangan Teknologi Pertanian, Bogor.

Wiryanta, B. (2002). Bertanam cabai pada musim hujan. Agromedia, Jakarta.

Wisudawaty, P., Yuliasih, I. \& Haditjaroko, L. (2016). Pengaruh edible coating terhadap kapasitas air terikat sekunder dan tersier manisan tomat Cherry selama penyimpanan. J. Tekn. Industri Pertanian, 26(3): 301-310. 